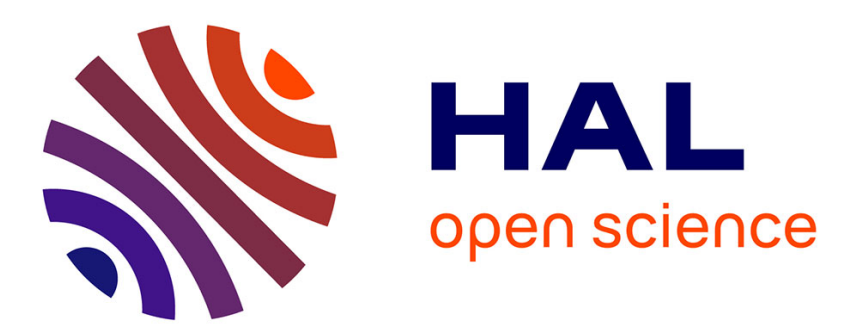

\title{
Feasibility of Heartbeat Detection Behind a Wall Using CW Doppler Radar
}

\author{
Sarah El-Samad, Dany Obeid, Gheorghe Zaharia, Sawsan Sadek, Ghaïs El \\ Zein
}

\section{- To cite this version:}

Sarah El-Samad, Dany Obeid, Gheorghe Zaharia, Sawsan Sadek, Ghaïs El Zein. Feasibility of Heartbeat Detection Behind a Wall Using CW Doppler Radar. 3rd Middle East Conference on Antennas and Propagation (MECAP'16), Sep 2016, Beyrouth, Lebanon. 10.1109/mecap.2016.7790091 . hal01369511

\section{HAL Id: hal-01369511 \\ https://hal.science/hal-01369511}

Submitted on 21 Sep 2016

HAL is a multi-disciplinary open access archive for the deposit and dissemination of scientific research documents, whether they are published or not. The documents may come from teaching and research institutions in France or abroad, or from public or private research centers.
L'archive ouverte pluridisciplinaire HAL, est destinée au dépôt et à la diffusion de documents scientifiques de niveau recherche, publiés ou non, émanant des établissements d'enseignement et de recherche français ou étrangers, des laboratoires publics ou privés. 


\title{
Feasibility of Heartbeat Detection Behind a Wall Using CW Doppler Radar
}

\author{
Sarah El-Samad ${ }^{1,2}$, Dany Obeid ${ }^{1}$, Gheorghe Zaharia ${ }^{2}$, Sawsan Sadek ${ }^{1}$, Ghaïs El Zein ${ }^{2}$ \\ ${ }^{1}$ Doctoral School of Science and Technology, Lebanese University, Lebanon \\ ${ }^{2}$ IETR - UMR CNRS 6164, INSA Rennes, France
}

\begin{abstract}
This paper presents a wireless measurement system for cardiopulmonary activity detection behind a wall. This system generates a continuous wave signal and is used at 2 different frequencies: $2.4 \mathrm{GHz}$ and $10 \mathrm{GHz}$. The transmitted signal is directed toward the patient's chest situated at $1 \mathrm{~m}$ and then reflected. The radar system is based on a vector network analyzer, which measures the phase of $S_{21}$. The phase variation of $S_{21}$ contains information about heart and respiration activity. Measurements are carried out every 30 seconds, for a person sitting at a distance of 1 meter, directly in front of the system or behind a wall. Discrete wavelet transform is used as a processing technique to separate heartbeat signal from respiratory signal. The measurements were performed simultaneously with a PCbased electrocardiogram (ECG) which is used as a reference to validate the information extracted from the measured signals.
\end{abstract}

Keywords-heartbeat detection; continuous wave Doppler radar; electrocardiogram; heart rate; behind wall

\section{INTRODUCTION}

Contactless monitoring of vital signs is needed in medical surveillance applications and in healthcare [1], especially for burn patients and newly born. In addition, it can be very useful for detecting signs of life of people buried under rubble after an earthquake or tornado.

Non-contact microwave radar sensors have advantages over other contactless measurement systems like those based on video technologies, as microwave radar has sensibility towards tiny movements due to heartbeat and respiration. In addition, Doppler characteristics reveal extra details of motion, and thus enable gesture recognition [2]. Several radar types are used for the vital signs detection like ultra-wideband (UWB) radars, frequency modulated continuous wave (FMCW) radars, and continuous wave (CW) Doppler radars. Each of these radar technologies can be used to measure the Doppler shift and has its own advantages and disadvantages. Here, the CW Doppler radar is used because of its accuracy in the detection of vital signs and its ability to overcome the problem of clutter [3]. The Doppler radar first captures the chest motion. Then the human heartbeat and respiration rates are identified by signal processing techniques [4].

Several processing techniques are applied to separate heartbeat and respiratory signals based on band-pass filters [5], continuous-wavelet filters and ensemble empirical mode decomposition (EEMD) [6], and LMS adaptive harmonic cancellation algorithm [7].

In most of the previous studies, continuous wave Doppler radar was used for detecting vital signs of human subjects in indoor environments, hence the SNR was high. When the Doppler radar works outdoor, the SNR of the radar echo signal becomes low and it may be difficult to extract vital signs. However, detecting vital signs throw wall is highly desirable for a range of organizations, including police, fire, rescue personnel and defense forces to allow the detection even behind an obstacle [8].

In this work, heartbeat rate has been extracted using continuous wave Doppler radar in the presence of a separation wall for a person who breathes normally at $1 \mathrm{~m}$ from the system. To validate our measurement system and the selected signal processing techniques, as in [9], measurements were performed simultaneously with a PC-based electrocardiogram used as a reference system.

The rest of this paper is organized as follows: Section II gives background information; Section III describes the measurement system. Section IV presents the data processing techniques. Obtained results are summarized and discussed in Section V. Finally, Section VI gives some concluding remarks.

\section{BACKGROUND INFORMATION}

According to the Doppler effect, when the radar signal is reflected by a target having a quasi-periodic motion, its phase will be modulated by the time-varying position of the target [10]. The relation between target displacement $\Delta x(t)$ and the phase variation $\Delta \theta(t)$ is:

$$
\Delta \theta(t)=\frac{4 \pi \Delta x(t)}{\lambda}
$$

where $\lambda$ is the wavelength of the transmitted signal [5].

The person's chest is the target; and the reflected signal contains information about the chest displacement due to heartbeat and respiration. When breathing normally, the peak to peak variation of the chest is between 4 and $12 \mathrm{~mm}$ [10]. It is caused by respiration. When holding breath, the range of the chest displacement is between 0.2 and $0.5 \mathrm{~mm} \mathrm{[10].} \mathrm{In} \mathrm{this}$ case, the chest displacement is due to heartbeat only. Table I presents frequencies $(\mathrm{Hz})$, heartbeat rates (beat per minute) and respiration per minute for each case.

In this paper, measurements are done on adult persons; hence the frequency range is between 1 and $2 \mathrm{~Hz}$. This work presents the heartbeat detection in the presence of a barrier. Barriers cause attenuation: $\alpha$ and $\beta$ represent attenuation and phase constants, respectively [8]. 
TABLE I. FREQUENCIES AND RATES OF RESPIRATION AND HEARTBEAT

\begin{tabular}{|c|c|c|}
\hline Case & $\begin{array}{c}\text { Frequency } \\
\text { (Hz) }\end{array}$ & $\begin{array}{c}\text { Rate } \\
\text { (breathes or } \\
\text { beats /min) }\end{array}$ \\
\hline Respiration & 0.1 to 0.3 & 6 to 18 \\
\hline Heartbeat & 1 to 3 & 60 to 180 \\
\hline $\begin{array}{c}\text { Adult } \\
\text { Heartbeat }\end{array}$ & 1 to 2 & 60 to 120 \\
\hline $\begin{array}{c}\text { Babies } \\
\text { heartbeat }\end{array}$ & 2 to 3 & 120 to 180 \\
\hline
\end{tabular}

They can be expressed in terms of the material properties and frequency as:

$$
\begin{aligned}
& \alpha=\omega \sqrt{\frac{\mu \varepsilon_{0} \varepsilon_{r}^{\prime}}{2}}\left[\sqrt{1+\left(\frac{\sigma_{e}}{\omega \varepsilon_{0} \varepsilon_{r}^{\prime}}\right)^{2}}-1\right]^{\frac{1}{2}} \\
& \beta=\omega \sqrt{\frac{\mu \varepsilon_{0} \varepsilon_{r}^{\prime}}{2}}\left[\sqrt{1+\left(\frac{\sigma_{e}}{\omega \varepsilon_{0} \varepsilon_{r}^{\prime}}\right)^{2}}+1\right]^{\frac{1}{2}}
\end{aligned}
$$

where $\omega$ is the angular frequency, $\mu$ is the permeability, $\varepsilon_{r}^{\prime}$ is the real part of the relative permittivity. It accounts for the energy storing capability of the material. $\varepsilon_{0}$ is the permittivity of free space and $\sigma_{e}$ is the effective conductivity. $\sigma_{e}$ is the sum of static conductivity $\sigma_{s}$ which is responsible for the material's ohmic losses and ac field conductivity $\sigma_{a}$ that is responsible to the heating of the dielectric material caused by the dipole oscillations [8]. Based on the formulas, the attenuation may be significant when the frequency increase, hence the error increase when the frequency increase. In addition, this attenuation should cause the augmentation of error relatively to the absence of the barrier.

\section{MEASUREMENT SYSTEM}

The measurement system is based on a vector network analyzer (VNA) and two horn antennas. Fig. 1 presents the system used for detecting vital signs of a person behind a wall.

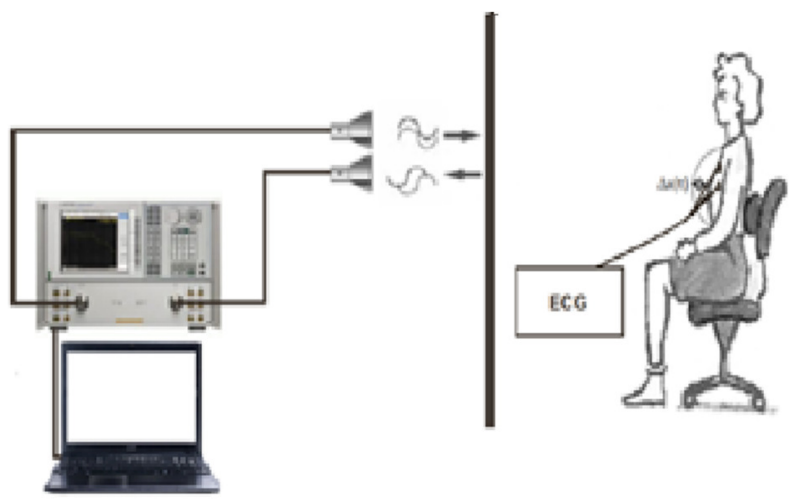

Fig. 1. Measurement system for a person behind a wall.

The VNA is used to measure the time variation of the phase of the $S_{21}$ parameter. $S_{21}$ corresponds to the difference between the phases of the received and transmitted signals.
The frequencies of the transmitted $\mathrm{CW}$ signal chosen for this study are: $2.4 \mathrm{GHz}$ (ISM S-band) and $10 \mathrm{GHz}$ (X-band). This choice allows to compare the accuracy of the results obtained using these frequencies. The horn antennas used in this experiment are the Q-par Angus Ltd (model number WBH2-18HN/S) operating between 2 and $18 \mathrm{GHz}$. The gain of the antennas is $11 \mathrm{~dB}$ at $2.4 \mathrm{GHz}$ and $19 \mathrm{~dB}$ at $10 \mathrm{GHz}$. The total transmitted power is $1 \mathrm{~mW}(0 \mathrm{dBm})$. The radiated power of the antenna in $\mathrm{dBm}$ is the addition of the transmitted power of the VNA $(\mathrm{dBm})$ and the gain of the antenna $(\mathrm{dB})$; hence the radiated power is $11 \mathrm{dBm}$ at $2.4 \mathrm{GHz}$ and $19 \mathrm{dBm}$ at $10 \mathrm{GHz}$. During 30 seconds, 20000 points have been recorded. Hence, the sampling frequency is $666.7 \mathrm{~Hz}$.

A 54 years old person is sitting behind a concrete wall with $10 \mathrm{~cm}$ thickness. The distance between the antennas system and the wall is $0.5 \mathrm{~m}$ and the distance between the wall and the person is $0.5 \mathrm{~m}$. The person is breathing normally.

To validate the proposed system and the ability of the system to detect heartbeat rate behind wall, the radar system measurements are performed simultaneously with ECG measurements. Fig. 2 presents the peak detection of the ECG signal for a window of $10 \mathrm{~s}$. It is taken at the same moment when the person is setting behind wall with an emitted frequency equal to $2.4 \mathrm{GHz}$. Hence, 42 peaks are detected.

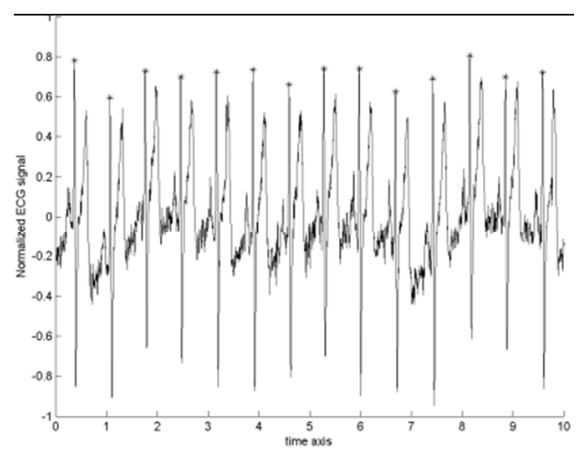

Fig. 2. Peak detection of an ECG signal.

Fig. 3 presents the phase variation (deg) of $S_{21}$ for a person who is sitting in front of the system at $2.4 \mathrm{GHz}$ and $10 \mathrm{GHz}$ and for a person sitting in front of the system without and with a barrier (wall) for 2 different frequencies: $2.4 \mathrm{GHz}$ and 10 GHz. These signals represent the cardiorespiratory signal.
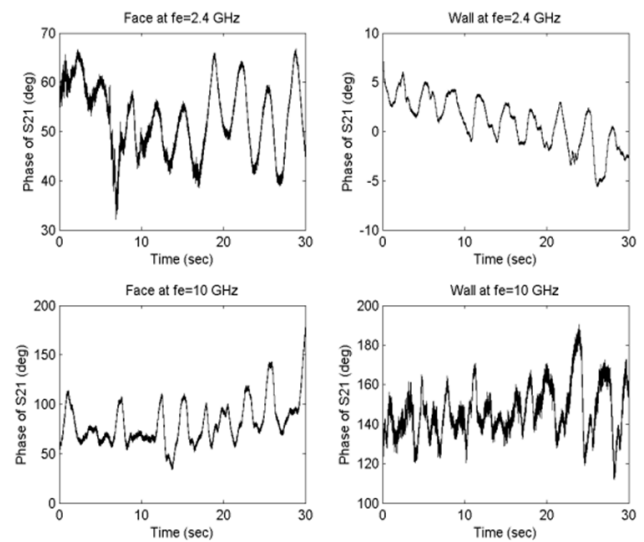

Fig. 3. Phase of $S_{21}(\mathrm{deg})$. 


\section{PROCESSING TECHNIQUES}

Processing technique is required in this work because respiratory amplitude is much larger than heartbeat amplitude; hence wavelet transform is chosen as processing technique for heartbeat extraction. This transform is a powerful tool to analyze non-stationary signals because it gives a good localization in time at high frequencies and good localization in frequency at low frequencies [11]. Two types of wavelets can be used: 'Discrete Wavelet Transform' and 'Continuous Wavelet Transform'. In this paper, 'Discrete Wavelet Transform' (DWT) is used. DWT is computed by successive low-pass and high-pass filtering of the discrete time-domain signal [12]. After the low-pass filtering the signal corresponds to the approximation $\left(A_{n}\right)$ while after the high-pass filtering the signal corresponds to the detail $\left(D_{n}\right)$. For a signal having a sampling frequency $f_{s}, D_{n}$ contains frequencies between $f_{s} / 2^{\mathrm{n}+1}$ and $f_{s} / 2^{\mathrm{n}}$ and $A_{n}$ contains frequencies between 0 and $f s / 2^{\mathrm{n}+1}$.

By assembling the decompositions and approximations, the original signal is reconstructed. The relation (2) gives the reconstructed signal

$$
S_{\text {reconstructed }}=A_{N}+D_{N}+\cdots . .+D_{2}+D_{1}
$$

where $N$ denotes the maximum level of decomposition.

There are different families of wavelets. Families of wavelets make different trade-offs between how compactly the basic functions are localized in space and how smooth they are. Each family of wavelets has subclasses distinguished by the number of coefficients and by the level of iterations [10]. All families give reasonable results. Because Daubechies 5 gives better results. It is chosen as wavelet family.
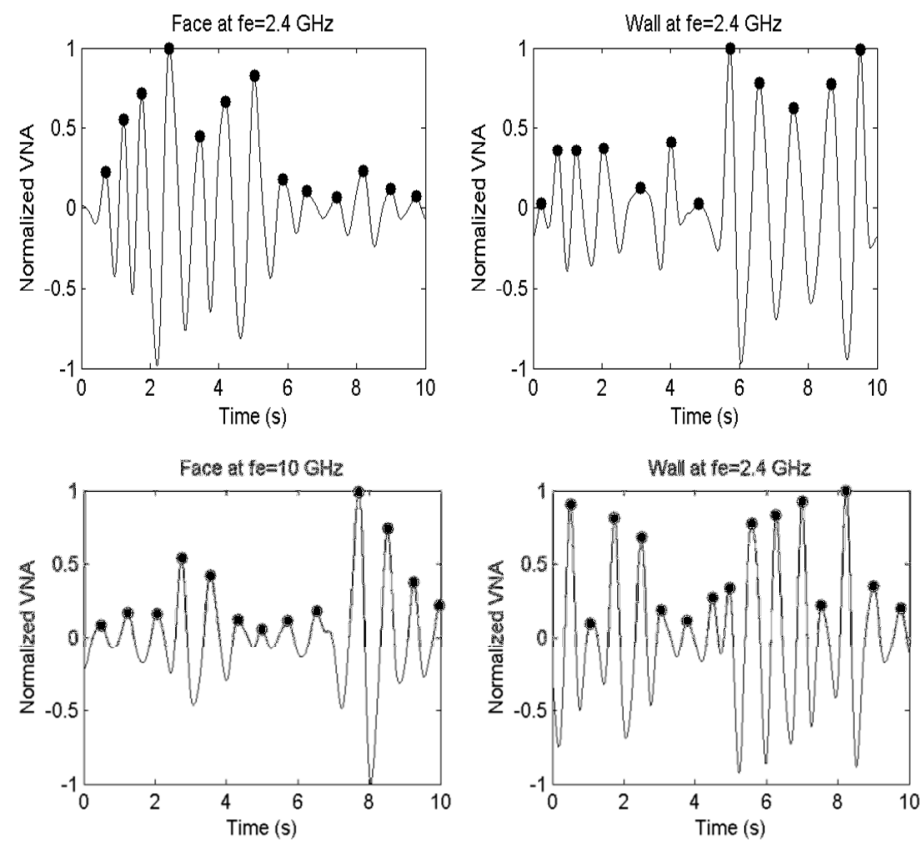

Fig. 4. Peak detection applied on $D_{8}$.

Because heartbeat rate is between 60 and 120 beats per minute, which corresponds to a frequency between 1 and 2
$\mathrm{Hz}$, resampling method should be applied before wavelet decomposition to finally obtain a decomposition having frequencies between 1 and $2 \mathrm{~Hz}$. In this work, the resampling method is used to convert the sampling frequency from 666.7 $\mathrm{Hz}$ to $512 \mathrm{~Hz}$.

In conclusion, $D_{8}$ contains the frequencies between 1 and 2 Hz. Peak detection is applied on $D_{8}$. Fig. 4 presents the peak detection applied on $D_{8}$ for the results obtained at $2.4 \mathrm{GHz}$ and $10 \mathrm{GHz}$, with presence and absence of wall.

\section{RESULTS}

After peak detection of the heartbeat signal, parameters are extracted. The parameter extracted in this work is the heartbeat rate which is calculated using the relation (3):

$$
H R=\frac{60(N-1)}{d_{1}+d_{2}+\cdots+d_{N-1}}
$$

where $N$ is the peaks number and $d_{k}$ is the duration of the interval determined by 2 successive peaks expressed in seconds. Relative error $(R E)$ between the Heartbeat Rate extracted from the radar system $\left(H R_{V N A}\right)$ and that extracted from the ECG $\left(H R_{E C G}\right)$ is calculated by the relation (4):

$$
R E=100 \times \frac{H R_{V N A}-H R_{E C G}}{H R_{E C G}}
$$

Table II presents the heartbeat rates extracted from ECG and the VNA, as well as the relative error for each case and each emitted frequency.

TABLE II. HeArtbeat RATE EXTRACTEd From ECG AND From VNA FoR EACH FREQUENCY AND EACH CASE

\begin{tabular}{|c|c|c|c|c|}
\hline Case & $\begin{array}{c}\text { Frequency } \\
(\mathbf{G H z})\end{array}$ & $\begin{array}{c}\boldsymbol{H R}_{V N A} \\
(\mathbf{b p m})\end{array}$ & $\begin{array}{c}\mathbf{H R}_{\text {ECG }} \\
(\mathbf{b p m})\end{array}$ & $\begin{array}{c}\text { Relative } \\
\text { Error }(\boldsymbol{\%})\end{array}$ \\
\hline Direct & 2.4 & 83 & 81 & 2.46 \\
\hline Direct & 10 & 80 & 84 & 5 \\
\hline Behind wall & 2.4 & 76 & 85 & 10.58 \\
\hline Behind wall & 10 & 80 & 90 & 11.11 \\
\hline
\end{tabular}

Based on the American National Standard [13], the system is considered accurate when the relative error is lower than $10 \%$ or $5 \mathrm{bpm}$ difference between the reference ECG and the microwave system. In general, obtained results are acceptable. The relative errors for measures taken directly in front of the person are less than $5 \%$ and for those taken behind the wall are slightly less than $10 \%$.

\section{CONCLUSION}

In this paper, a CW Doppler radar system has been used for cardiopulmonary activity measurements in different cases. ECG is taken as a reference signal and compared to the VNA signals. The heartbeat rate is extracted from a person sitting at a distance of 1 meter from the system, with emitted frequencies 2.4 and $10 \mathrm{GHz}$ and in 2 cases: in presence and absence of wall. The system is able to detect the heartbeat signal at a distance of $1 \mathrm{~m}$ for both cases. Relative errors without wall are less than $5 \%$ and increase to $11 \%$ with presence of wall. Other measures can be done to ensure that daubechies 5 is better than other wavelet families and to 
ensure that relative error increase when frequency increase with presence of barrier. Future work will focus on determining the heartbeat rate of the person in movement and behind an obstacle.

\section{ACKNOWLEDGMENT}

The authors acknowledge LASER (Lebanese Association for Scientific Research) for funding this study, and "Rennes Metropole" for partially funding this work.

\section{REFERENCES}

[1] J. Kuutti, M. Paukkunen, M. Aalto, P. Eskelinen, R. E. Sepponen, Evaluation of a Doppler radar sensor system for vital signs detection and activity monitoring in a radio frequency shielded room, Measurement, Vol. 68, May 2015, pp. 135-142.

[2] G. Wang, C. Gu, C. Li, "Application of Linear Continuous Wave (LFMCW) Radars for Tracking of Vital Signs," Microwave Theory and Techniques, IEEE Transactions on, Vol. 62, (Issue: 6), November 2014, pp. 2812-2822.

[3] G. Wang, C. Gu, T. Inoue, C. Li, A hybrid FMCW- Interferometry Radar for indoor precise positioning and versatile life activity monitoring, Microwave Theory and Techniques, IEEE Transactions, Vol. 62, (Issue: 11), November 2014, pp. 2812-2822.

[4] S. El-Samad, D. Obeid, G. Zaharia, S. Sadek, G. El Zein, Contact-Less measurement system or cardiopulmonary activity, Proc. of 2014 Mediterranean Microwave Symposium.(MMS), 2014, December 2014, Marrakech.

[5] D. Obeid, G. Issa, S. Sadek, G. Zaharia, G. El Zein, "Low Power Microwave Systems for Heartbeat Rate Detection at 2.4, 5.8, 10 and 16 GHz," Proc. of the First International Symp. on Applied Sciences in
Biomedical and Comm. Technol. (ISABEL 2008), Aalborg, Denmark, October 2008

[6] M. A. Othman, H. Azman, M. N. Husain, M. M. Ismail, H. A. Sulaiman, M. H. Misran, M. A. M. Said, M. Abdulaziz, N. Hassan, A. N. Che Pee, S. Suhaimi, M. R. Motsidi, "Heart Monitoring Systems at $10 \mathrm{GHz}$ Using Microwave Doppler Techniques for Atheletes Fitness Monitoring System: A Review," Australian Journal of Basic and Applied Sciences, Vol. 7, (Issue: 14), December, 2013, pp. 57-70.

[7] H. Zhang, S. Li, X. Jing, P. Zhang, Y. Zhang, T. Jiao, G. Lu, J. Wang, The Separation of the Heartbeat and Respiratory Signal of a Doppler Radar Based on the LMS Adaptive Harmonic Cancellation Algorithm, International Symposium on Computational Intelligence and Design (ISCID), October 2013, Hangzhou.

[8] A. H. Muqaibel, M. A. Alsunaidi, N. M. Iya, A. Safaai-Jazi, "Wall Attenuation and Dispersion", In book "Through the wall: Radar imaging", CRC Press, Ch. 1, pp. 1-32, 2010

[9] D. Obeid, G. Zaharia, S. Sadek, G. El Zein, "Microwave Doppler radar for heartbeat detection vs electrocardiogram," Microwave and Optical Technology Letters, Vol. 54, (Issue: 11), November 2012, pp.2610-2617.

[10] D. Obeid, S. Sadek, G. Zaharia, G. El Zein, "A tunable-frequency system for touch-less heartbeat detection and HRV extraction," Proc. of IEEE ISSCS, Iasi, Romania, July 2009, 4p.

[11] A.I. Megahed, A. Monem Moussa, H. B. Elrefaie, Y.M. Marghany, "Selection of a Suitable Mother Wavelet for Analyzing Power System Fault Transients", Power and Energy Society General Meeting Conversion and Delivery of Electrical Energy in the 21st Century, Pittsburgh, PA, July 2008, 7p.

[12] G. A. Blackburn, J. Garke Ferwerda, Retrieval of chlorophyll concentration from leaf reflectance spectra using wavelet analysis, Remote Sensing of Environment, Vol. 112, (Issue: 4), April 2008, pp.1614-163.

[13] American National Standard, Cardiac monitors, heart rate meters, and alarms (ANSI/ AAMI EC1, 2002). 